\title{
Commentary: It is not as bad as they say: The risks of surgery in screening-detected lung cancer are overstated
}

\author{
Michael K. Hsin, MD, and James C. Ho, MD
}

\author{
From the Department of Cardiothoracic Surgery, Queen Mary Hospital, Hong Kong, China; and Department of \\ Medicine, Hong Kong University, Hong Kong, China. \\ Disclosures: Authors have nothing to disclose with regard to commercial support. \\ Received for publication Dec 8, 2018; accepted for publication Dec 10, 2018; available ahead of print Jan 28, \\ 2019. \\ Address for reprints: Michael K. Hsin, MD, Department of Cardiothoracic Surgery, Queen Mary Hospital, 102 \\ Pok Fu Lam Rd, High West, Hong Kong, China (E-mail: mkhsin@ hotmail.com). \\ J Thorac Cardiovasc Surg 2019;157:2047-8 \\ $0022-5223 / \$ 36.00$ \\ Copyright (c) 2019 by The American Association for Thoracic Surgery \\ https://doi.org/10.1016/j.jtcvs.2018.12.043
}

The goal of a cancer screening program is to target an at-risk population of individuals without any symptoms and thus to detect cancer at an early stage, when timely treatment may be beneficial. The National Lung Screening Trial (NLST) showed a $20 \%$ reduction of lung cancer mortality, and a $6.7 \%$ reduction in all-cause mortality, when using lowdose CT (LDCT) rather than chest x-ray screening. ${ }^{1} \mathrm{Be}-$ tween 2010 and 2015, however, only 3.9\% of eligible patients were screened for lung cancer in the United States. ${ }^{2}$ Reasons put forward to explain this low uptake of LDCT screening include the following:

1. Several European studies (Danish Lung Cancer Screening Trial, Multi-centric Italian Lung Detection Trial, Detection and Screening of Early Lung Cancer with Novel Imaging Technology and Molecular Assays) failed to demonstrate lung cancer mortality benefit with screening. ${ }^{3-5}$

2. Cost-effectiveness of LDCT screening may not be acceptable in many countries.

3. There are concerns regarding the risks associated with LDCT screening. These include radiation, false positives, overtreatment, and, importantly, the morbidity of surgical procedures as a result of screening detected abnormalities, which in the NLST was reported to be $32 \%$.

The study in this issue of the Journal by Kemal and colleagues, ${ }^{6}$ which focuses on the surgical patients in the NLST cohort, should allay some of the concerns regarding the risks of surgery in patients with screening-detected lung cancer. The NLST did not have a predefined management protocol for screening-detected abnormalities, and, not surprisingly given the era of the study, Kemal and colleagues, ${ }^{6}$ found low use of preoperative positron-emission tomography and nonsurgical biopsy. Lobectomy or pneumonectomy was performed in $83.98 \%$ of the cases, and $16.1 \%$ of the patients had sublobar resection. Video-assisted thoracoscopic surgery was the surgical approach in $29.6 \%$ of the cases. With respect to complications after surgery for lung

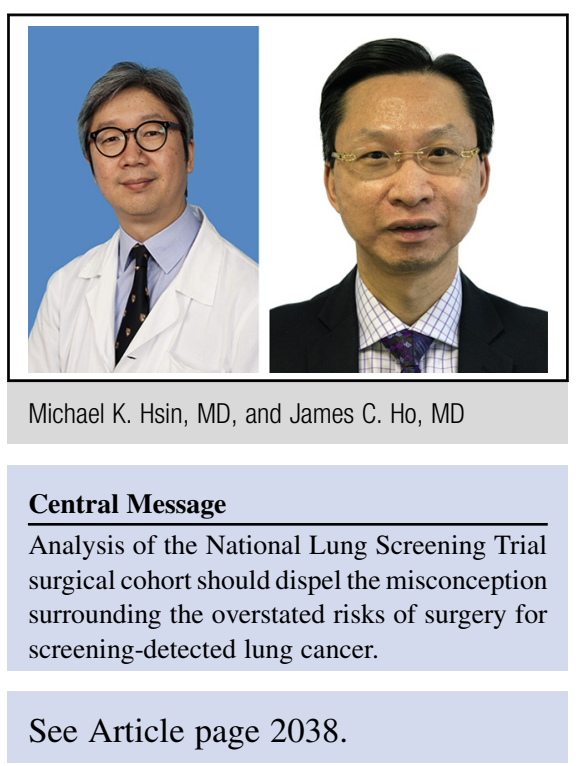

cancer, $15.5 \%$ were classified as major, of which the most common category was prolonged air leak or bronchial stump leak $(6.5 \%$ of the cohort and $42 \%$ of the "major complications"). The NLST data set did not differentiate between these types of leak; however, it is highly probable that bronchial stump leak was uncommon. For the remaining major complications, respiratory failure occurred in $3.7 \%$, major adverse cardiovascular events in $0.8 \%$, and cerebrovascular accident in $1 \%$. Overall 30-day mortality was reassuringly low at $1.7 \%$. On multivariate analysis, the use of sublobar resection was significantly associated with decreased complications, and the use of video-assisted thoracoscopic surgery approached significance.

As far as the conflicting data on mortality benefits of lung cancer screening are concerned, the recently presented findings of the NEderlands Leuvens Longkanker Screenings Onderzoek (NELSON), a Dutch-Belgian randomized, controlled trial, reconfirmed the benefits of computed tomographic screening. ${ }^{7}$ Relative to a control population, men at high risk of lung cancer had a $26 \%$ reduction in lung cancer-related death at 10 years; in women, the reduction was between $39 \%$ and $61 \%$ at different years of followup. Important differences between NELSON and NLST include the use of computed tomographic volumetry and a protocolized algorithm for the management of screeningdetected nodules.

The study of Kemal and colleagues ${ }^{6}$ should dispel some of the misguided concerns regarding the risks of surgery 
associated with screening. Post hoc analysis of NLST data suggests decreased complications with the use of sublobar resection and video-assisted thoracoscopic surgery. Standardized computed tomographic volumetry-with or without artificial intelligence technology, protocolized management algorithm of lung nodules, and state-of-theart surgical techniques-should be incorporated in future designs of LDCT lung screening programs.

\section{References}

1. National Lung Screening Trial Research Team, Church TR, Black WC, Aberle DR, Berg CD, Clingan KL, et al. Results of initial low-dose computed tomographic screening for lung cancer. N Engl J Med. 2013; 368:1980-91.

2. Jemal A, Fedewa SA. Lung cancer screening with low-dose computed tomography in the United States-2010 to 2015. JAMA Oncol. 2017;3:1278-81.
3. Pedersen JH, Ashraf H, Dirksen A, Bach K, Hansen H, Toennesen P, et al. The Danish randomized lung cancer CT screening trial-overall design and results of the prevalence round. J Thorac Oncol. 2009;4:608-14.

4. Pastorino U, Rossi M, Rosato V, Marchianò A, Sverzellati N, Morosi C, et al. Annual or biennial CT screening versus observation in heavy smokers: 5-year results of the MILD trial. Eur J Cancer Prev. 2012;21:308-15.

5. Infante M, Lutman FR, Cavuto S, Brambilla G, Chiesa G, Passera E, et al; DANTE Study Group. Lung cancer screening with spiral CT: baseline results of the randomized DANTE trial. Lung Cancer. 2008;59:355-63.

6. Kamel M, Lee B, Harrison S, Port JL, Pua B, Altorki NA, et al. Do the surgical results in the national lung screening trial reflect modern thoracic surgical practice? J Thorac Cardiovasc Surg. 2019;157:2038-46.e1.

7. De Koning H, Van Der Aalst CM, ten Haaf K, Oudkerk M. Effects of volume CT lung cancer screening: mortality results of the NELSON randomised-controlled population based trial. Presented at: International Association for the Study of Lung Cancer (IASLC) 19th World Conference on Lung Cancer (WCLC); September 25, 2018; Toronto, Ontario, Canada. Available at: https://ibrary.iaslc.org/conferenceprogram?product_id $=10 \&$ author $=\&$ category $=\&$ date $=\&$ session_type $=\&$ session $=$ \&presentation $=\&$ keyword $=$ koning\&. Accessed January 13, 2019. 